\section{Complexity of Coupled Human and Natural Systems}

\author{
Jianguo Liu, ${ }^{{ }^{*}}$ Thomas Dietz, $^{2}$ Stephen R. Carpenter, ${ }^{3}$ Marina Alberti, ${ }^{4}$ Carl Folke, ${ }^{5,6}$ \\ Emilio Moran, ${ }^{7}$ Alice N. Pell, ${ }^{8}$ Peter Deadman, ${ }^{9}$ Timothy Kratz, ${ }^{10}$ ]ane Lubchenco, ${ }^{11}$ \\ Elinor Ostrom, ${ }^{12}$ Zhiyun Ouyang, ${ }^{13}$ William Provencher, ${ }^{14}$ Charles L. Redman, ${ }^{15}$ \\ Stephen H. Schneider, ${ }^{16}$ William W. Taylor $^{1}$
}

Integrated studies of coupled human and natural systems reveal new and complex patterns and processes not evident when studied by social or natural scientists separately. Synthesis of six case studies from around the world shows that couplings between human and natural systems vary across space, time, and organizational units. They also exhibit nonlinear dynamics with thresholds, reciprocal feedback loops, time lags, resilience, heterogeneity, and surprises. Furthermore, past couplings have legacy effects on present conditions and future possibilities.

$\mathrm{C}$ oupled human and natural systems are integrated systems in which people interact with natural components. Although many studies have examined human-nature interactions $(1-5)$, the complexity of coupled systems has not been well understood $(6,7)$. The lack of progress is largely due to the traditional separation of ecological and social sciences (8). Although some scholars have studied coupled systems as complex adaptive systems $(9,10)$, most of the previous work has been theoretical rather than empirical.

An increasing number of interdisciplinary programs have been integrating ecological and social sciences to study coupled human and natural systems (e.g., social-ecological systems and human-environment systems). Here, we synthesize six case studies to demonstrate the approaches used and results found (Fig. 1 and table S1).

${ }^{1}$ Center for Systems Integration and Sustainability, Department of Fisheries and Wildlife, Michigan State University, East Lansing, MI 48824, USA. ${ }^{2}$ Environmental Science and Policy Program, Michigan State University, East Lansing, MI 48824, USA. ${ }^{3}$ Center for Limnology, University of Wisconsin Madison, WI 53706, USA. ${ }^{4}$ Department of Urban Design and Planning, University of Washington, Seattle, WA 98195 USA. ${ }^{5}$ The Beijer International Institute of Ecological Economics, The Royal Swedish Academy of Sciences, Post Office Box 50005, SE 10405 Stockholm, Sweden. ${ }^{6}$ Stockholm Resilience Centre, Stockholm University, SE 10691 Stockholm, Sweden. ${ }^{7}$ Department of Anthropology, Indiana University, Bloomington, IN 47405, USA. ${ }^{8}$ Cornell International Institute for Food, Agriculture, and Development, Cornell University, Ithaca, NY 14853, USA. ${ }^{9}$ Department of Geography, University of Waterloo, Waterloo, Ontario N2L 3G1, Canada. ${ }^{10}$ Trout Lake Station, University of Wisconsin, Boulder Junction, WI 54512, USA. ${ }^{11}$ Department of Zoology, Oregon State University, Corvallis, OR 97331, USA. ${ }^{12}$ Workshop in Political Theory and Policy Analysis, Indiana University, Bloomington, IN 47408-3895, USA. ${ }^{13}$ Research Center for Eco-Environmental Sciences, Chinese Academy of Sciences, Beijing, 100085, China. ${ }^{14}$ Department of Agricultural and Applied Economics, University of Wisconsin, Madison, WI 53706, USA. ${ }^{15} \mathrm{Global}$ Institute for Sustainability, Arizona State University, Tempe, AZ 85287-3211, USA. ${ }^{16}$ Department of Biological Sciences, Stanford University, Stanford, CA 94305-5020, USA.

*To whom correspondence should be addressed. E-mail: jliu@panda.msu.edu
These studies are on five continents: the Kenyan Highlands in Africa (Kenya); the Wolong Nature Reserve for giant pandas in China (Wolong); Central Puget Sound of Washington (Puget Sound) and Northern Highland Lake District of Wisconsin (Wisconsin) in the United States; an area near Altamira, State of Pará, Brazil (Altamira); and Kristianstads Vattenrike of Sweden (Vattenriket) (Fig. 1). They include urban (Puget Sound), semi-urban (Vattenriket), and rural areas (Altamira, Kenya, Wisconsin, and Wolong), and they are in developed countries (Puget Sound, Wisconsin, and Vattenriket) and developing countries (Altamira, Kenya, and Wolong). These studies are in different ecological, socioeconomic, political, demographic, and cultural settings, and they encompass a variety of ecosystem services and environmental problems (table S1)

These studies share four major features. First, they explicitly address complex interactions and feedback between human and natural systems. Unlike traditional ecological research that often excluded human impacts or social research that generally ignored ecological effects, these studies consider both ecological and human components as well as their connections. Thus, they measure not only ecological variables (e.g., landscape patterns, wildlife habitat, and biodiversity) and human variables (e.g., socioeconomic processes, social networks, agents, and structures of multilevel governance) (11), but also variables that link natural and human components (e.g., fuelwood collection and use of ecosystem services). Second, each study team is interdisciplinary, engaging both ecological and social scientists around common questions. Third, these studies integrate various tools and techniques from ecological and social sciences as well as other disciplines such as remote sensing and geographic information sciences for data collection, management, analysis, modeling, and integration (11-15) (table S1). Fourth, they are simultaneously contextspecific and longitudinal over periods of time long enough to elucidate temporal dynamics. As such, these studies have offered unique interdisciplinary insights into complexities that cannot be gained from ecological or social research alone.

\section{Reciprocal Effects and Feedback Loops}

In coupled human and natural systems, people and nature interact reciprocally and form complex feedback loops. For example, local residents in Wolong use forests as fuelwood for cooking and heating. As forests near households were depleted due to fuelwood collection (16), local residents had to collect fuelwood from areas far away (17). Because these forests are bamboo forests (habitat for the endangered giant panda) and the bamboo in the forests is the staple food for the panda, fuelwood collection has led to substantial deterioration in forests and panda habitat (16). To prevent further degradation and restore panda habitat, the Chinese government began to implement three major conservation policies several years ago, which help both local residents and panda habitat. In Kenya, local residents convert forests into cropland and intensively cultivate land without supplying additional nutrients, in some cases for more than 100 years. Soil degradation with the resulting decreases in crop yields and greater food insecurity hastens conversion of remaining forests to agriculture. Similarly, in Altamira, 255,739 hectares (ha) of forests had been converted into pasture and cropland as of 2003. As soil quality declines, fertilizers must be applied, crops are shifted to those with lower nutrient requirements, or more forests are converted into cropland (there were still 136,913 ha of forested area in 2003).

Feedback between human and natural systems in the agricultural and tourism sectors of developed countries is in many ways similar to feedback in developing countries. For example, local people (76,000 in 2005) in Vattenriket benefit from ecosystem services that are the result of long-term human management of the agricultural landscape. In Wisconsin, ecosystem conditions affect tourism, which is the mainstay of the economy, but economic development and ecosystem exploitation from tourism often degrade the qualities that attract tourists.

The ecological and socioeconomic patterns and processes in urban coupled systems are different from those in rural areas. They are mediated by factors such as the urban form, built infrastructure, and location and consumption preferences of heterogeneous households and businesses. For example, in Puget Sound, a distinctive spatial heterogeneity can be observed across an urban to rural gradient in relation to diverse development patterns (18). Land-cover changes influence biophysical processes (e.g., water purification) and stream biotic integrity (15). Furthermore, changes in land cover due to development in turn affect land value and real estate markets, as evidenced by values of real estate having up to a $6.5 \%$ premium associated with forest cover (19). 
Dynamics of human-nature systems are influenced by many factors, including government policies and contextual factors in which local processes are shaped by larger-scale and ultimately global-scale processes (20). Both markets and governance can cause decisions made in one place to affect people and ecosystems far away. For instance, economic opportunities in cities attracted many local residents from Wolong to work in cities in the past several years, thus reducing fuelwood collection and consumption. Compared with the migrant workers in cities from Wolong, however, more than a thousand times more tourists from around the world increased the demand for fuelwood through consuming local products, whose production may require fuelwood and electricity.

\section{Nonlinearity and Thresholds}

Numerous relationships in coupled systems are nonlinear. In Wisconsin, for instance, fallen trees that provide critical fish habitat in lakes and streams drastically decrease when housing density exceeds about seven houses per kilometer of shoreline (Fig. 2). Bird richness in the Puget Sound landscape with single-family housing and fragments of native forest increases nonlinearly with forest cover and peaks when 50 to $60 \%$ of the land is forested (Fig. 3) (21).

Thresholds [transition points between alternate states (22)] are common forms of nonlinearity. In Vattenriket, an intentional participatory process mobilized stakeholders laying the groundwork for a shift from conventional management to adaptive co-management (23). Cultural values and environmental concerns prompted local stakeholders to build new knowledge, develop new visions and goals, and create new social networks. The result of these community activities was a new and more suitable governance system of adaptive co-management of the landscape.

System behaviors shift from one state to another over time (temporal thresholds) and across space (spatial thresholds). Altamira depicts a temporal threshold, whereas Wolong demonstrates a spatial threshold. Deforestation rates in Altamira are high during the first 5 to 7 years of settlement and then decrease rapidly. In Wolong, as the distance between locations of households and fuelwood collection sites increases, panda habitat decreases, reaching a minimum at a distance of approximately $1800 \mathrm{~m}$ (17). When the distance between households and fuelwood supplies is small, the total area for fuelwood collection is small and thus panda habitat is better protected. When the distance is large (>1800 m), fuelwood collection is scattered throughout a large region and affected areas can recover relatively quickly. When the distance is approximately $1800 \mathrm{~m}$, local residents' fuelwood demand is met by cutting most available trees and causes more habitat loss (17).

\section{Surprises}

When complexity is not understood, people may be surprised at the outcomes of humannature couplings. For example, smelt (Osmerus mordax) was initially introduced to Wisconsin as a prey species for game fish such as walleyes (Stizostedion vitreum), but smelt ate juvenile walleyes leading to loss of walleye populations. In Puget Sound, growth management policy has caused urban density to intensify inside the urban growth boundary while unintentionally facilitating sprawl outside the urban growth boundary.

Conservation policies can also generate unintended perverse results. In Wolong, for instance, high-quality panda habitat degraded faster after the area was established as a reserve than before the reserve's creation (24). To prevent

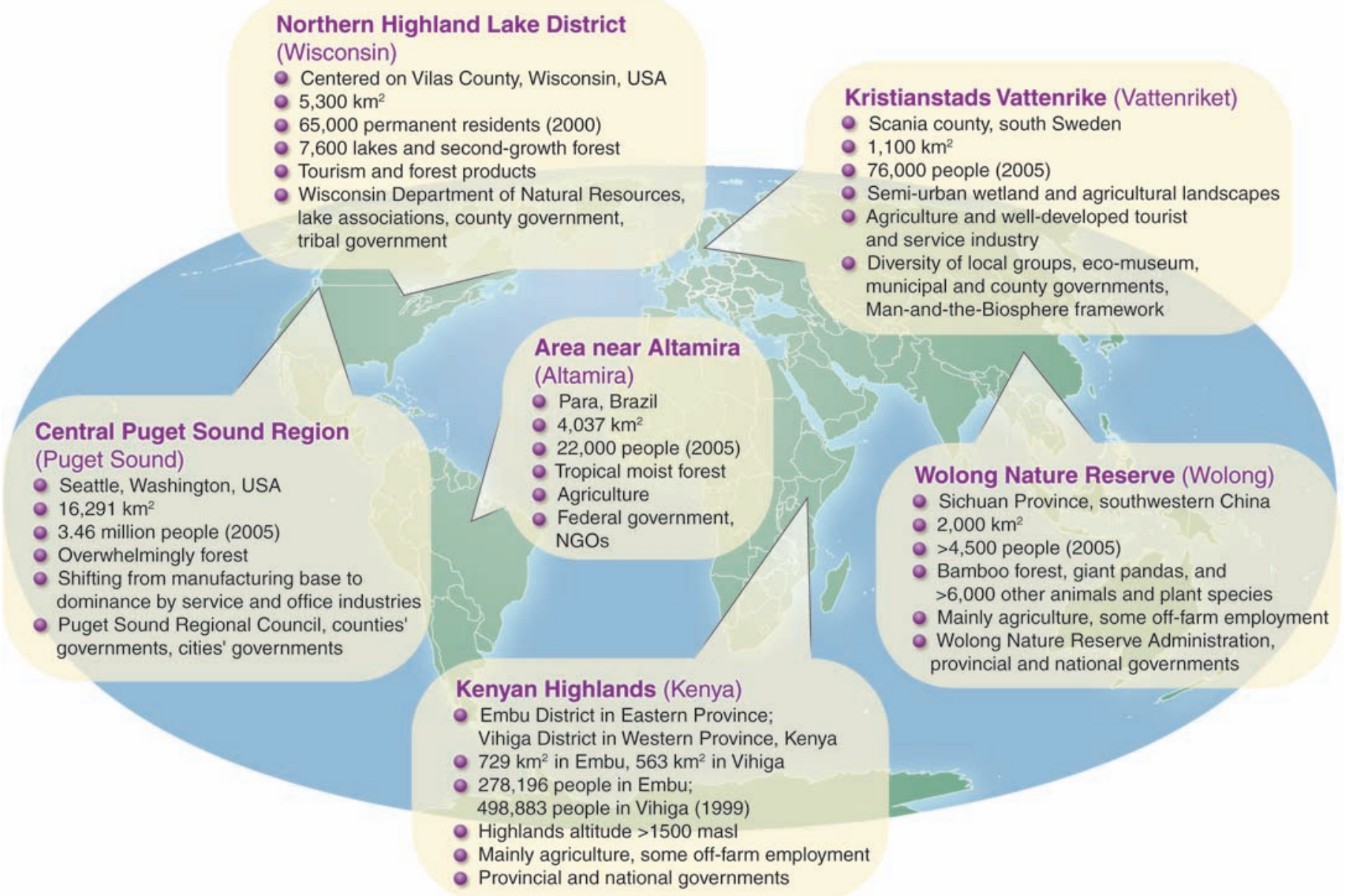

Fig. 1. Map highlighting major attributes of the six coupled human and natural systems (location; spatial extent; population size; and ecological, economic, and administrative attributes). To save space, short names within the parentheses represent the coupled systems. See table S1 for more detailed descriptions. 


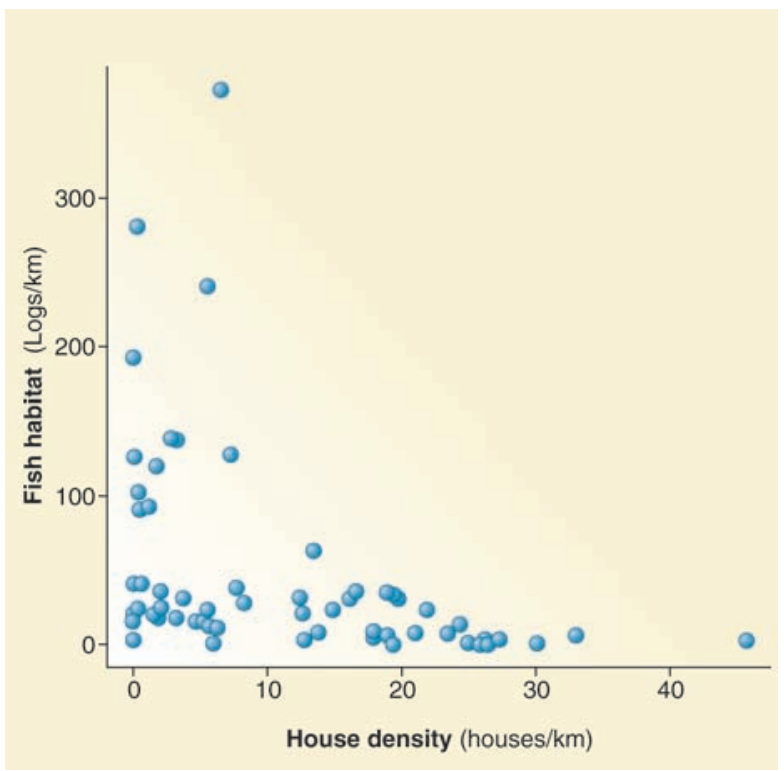

Fig. 2. The relationship between fish habitat (logs per kilometer) and house density in the Northern Highland Lake District of Wisconsin, United States. [modified from (38), with permission]

further degradation, a natural forest conservation program was introduced in 2001 for local residents to monitor illegal harvesting. Unexpectedly, a large number of new households formed in 2001 because many households decided to split into smaller ones to more effectively capture subsidies ( 20 to $25 \%$ of the average household income) given to households as part of the program. The household proliferation and reduction in household size (number of people in a household) increased demand for fuelwood and land for house construction (25).

Some ecosystems can only be sustained through human management practices, whereas many conservation efforts preclude such human interference. For example, the wetland site under the Ramsar Convention (an international treaty for the conservation and sustainable use of wetlands) in Vattenriket was set aside for conservation purposes, but the wetland became overgrown when grazing was halted. This unintended consequence led to an understanding of grazing as essential to maintaining this wetland system (23).

\section{Legacy Effects and Time Lags}

Legacy effects are impacts of prior human-nature couplings on later conditions. Among the six sites, legacies vary in duration from decades to centuries. The shortest legacy is in Altamira, a frontier area where the land tenure system imposed by the government in 1970 still shapes the present spatial pattern of land-cover change, human population distribution, and human activities. The longest legacy is in Vattenriket, where the landscape has been affected by human actions such as using wet grasslands over hundreds of years.

Legacy durations in the other sites fall somewhere in between. In Wolong, current forest types in areas at lower elevations $(1200$ to $3000 \mathrm{~m})$ are shaped by forest harvesting three to nine decades ago. Introduction of a keystone species can restructure a fish population for decades or longer, as has been demonstrated in the Wisconsin study area which started fish stocking in the 1930s. Long-term (up to 100 years) continuous cultivation in Kenya has decreased crop yields, with most of the degradation occurring during the first 15 to 20 years after conversion from forest to agriculture. In Puget Sound, landscape patterns are influenced by infrastructure built decades or even a century ago.

The ecological and socioeconomic impacts of humannature couplings may not be immediately observable or predictable because of time lags between the human-nature interactions and the appearance of ecological and socioeconomic consequences. In Kenya, there is a time delay between investment in soil improvement and increases in income. In Vattenriket, the city of Kristianstad stopped taking its drinking water from the Helgeå River in the 1940s because untreated industrial and household sewage had accumulated several decades earlier. Disturbances to groundwater quality can take a long time to appear "downstream" because groundwater movement between adjacent lakes can take centuries. In Puget Sound, ecological effects of the Growth Management Act adopted in the State of Washington in 1990 could not have been observed in less than 8 years (26).

The length of lags attributable to a single cause may vary for different indicators; conversely, different causes may become apparent over different time periods for the same indicator. The former can be seen in Altamira, where changes in crop prices quickly affect planting of annuals but effects on planting (or abandonment) of perennials (such as cocoa and black pepper) often are delayed. As to the latter situation, changes in the price of electricity quickly affect panda habitat in Wolong because of sharp changes in fuelwood demand, but spacing of births within households has a much slower effect (27). Energy for cooking is needed daily and fluctuations in the price for electricity may quickly force local residents to use more fuelwood (thus destroying forests and panda habitat), whereas it takes a longer time for children to establish new households that increase demand for energy.

\section{Resilience}

Coupled systems have different degrees of resilience - the capability to retain similar structures and functioning after disturbances for continuous development $(10,28,29)$. Resilience can be affected by many factors. In Wolong, for example, larger areas with fast-growing tree species are more resilient to fuelwood collection than are smaller areas with slower-growing trees. In Kenya, remittances from relatives employed in urban areas minimize food insecurity due to crop failures caused by droughts and poor soil fertility.

Human intervention also plays a key role in maintaining resilience. For instance, in Vattenriket, sustaining the resilience of the wetland landscape requires grazing by cattle and incentives to make grazing economically viable. Partially because of the actions of environmentalists, Puget Sound is still home to one of the last intact oldgrowth forests in the United States despite rapid urbanization. In Wisconsin, social-ecological resilience comes from the good condition of many ecosystems; the intention of Native Americans to manage their lands and lakes sustainably; the mosaic of tribal, private, and state ownership; and innovations in ecosystem management by various stakeholders (tribal governments of Native Americans, lake associations, formal

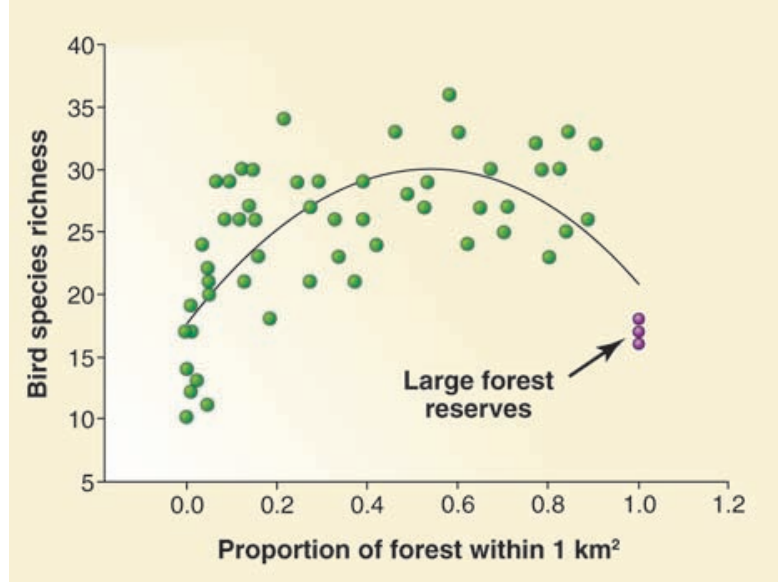

Fig. 3. Change in avian richness with progressively more forest (less human settlement) in the human-influenced landscape in Central Puget Sound region of Washington, United States. [modified from (21), with permission]

research organizations, and nongovernment organizations) (12).

\section{Heterogeneity}

Human-nature couplings vary across space, time, and organizational units. The socioeconomic differences among people in Wisconsin lead to different choices and behaviors, which in turn result in very different ecological outcomes than 
one would find were everyone to have the same preferences for ecosystem services. In Altamira, different settlement cohorts follow similar trajectories of land use, but the magnitude of changes in important variables like rates of deforestation varies as a product of exogenous and endogenous factors (e.g., local, regional, and global political economy) (30). For the Kenyan highlands, it is common to find families with soils of different quality and as a result, different crop yields.

Coupled human-natural systems are not static; they change over time. Although the human population sizes have increased in all six study sites over the past several decades, the resultant ecological impacts have differed. In the Kenya study area, human population size has doubled over the past 30 years, causing a marked reduction in farm size. Smaller farm size has led to growing maize during both rainy seasons to meet family demand, but this practice has accelerated the rate of soil degradation and increased poverty. An increase in recreational land use in Wisconsin led to a 4.6-fold increase in housing density (from 3.7 to 17.2 units $/ \mathrm{km}^{2}$ ) from 1940 to 2000. For Puget Sound, between 1991 and 1999 land area covered by development increased by $620 \mathrm{~km}^{2}$ (31.5\% increase), while forest cover declined by $714 \mathrm{~km}^{2}[10.3 \%$ decline (26)]. Temporal changes take place not only inside a coupled system, but also across its boundaries. In Wolong, a rapidly increasing number of domestic and foreign tourists have made the system much more tightly coupled to the national and global economy.

Spatial variations exist in all coupled systems. For example, more fuelwood is collected in areas of Wolong with easy access and little enforcement than in forested areas with more challenging topography or strict enforcement. In Vattenriket, habitats and management practices, local stewardship associations, social networks, and multilevel institutions vary across the landscape (11). Landscape heterogeneity of Puget Sound increases with the degree of urbanization, but differs substantially within the region depending on urban land-use patterns, infrastructure, and spatial distribution of activities (18). In Wisconsin, people have preferentially settled around lower-elevation lakes, which tend to have riverine inputs, low to moderate dissolved organic carbon, low to moderate nutrients, and relatively diverse sport fish communities (31). In Altamira, fertile soils permit cultivation of cocoa and sugar cane, whereas on poorer soils, pasture and manioc cultivation are more common.

\section{Conclusion and Outlook}

Results such as those reviewed here benefit from and help advance the integration of ecological and social sciences. The approaches used and the results from these studies can be applied to many other coupled systems at local, national, and global levels. For instance, the finding that the number of households increased faster than the human population size in Wolong over the past three decades has led to the discovery that this trend is global and is particularly profound in the 76 countries with biodiversity hotspots (25). The Lake Futures Project (32) in Wisconsin was a prototype used to develop approaches for the Millennium Ecosystem Assessment scenarios (33).

Comparison of these studies provides important insights into diverse complex characteristics that cannot be observed in a single study. The types of surprises found in the case studies differ, although all of them originated from the interactions between human and natural systems. All six studies have demonstrated legacy effects, but legacy durations varied from decades to centuries. Because of the independent nature of these studies, information from one study is not necessarily available in or transferable to other studies. To increase the extent of generalizing from case studies, future research on coupled systems must include not only separate sitespecific studies but also coordinated, long-term comparative projects across multiple sites to capture a full spectrum of variations $(14,34,35)$. Furthermore, all the studies in this review focus on interactions within the system, rather than interactions among different coupled systems. As globalization intensifies, there are more interactions among even geographically distant systems and across scales $(36,37)$. Thus, it is critical to move beyond the existing approaches for studying coupled systems, to develop more comprehensive portfolios, and to build an international network for interdisciplinary research spanning local, regional, national, and global levels.

\section{References and Notes}

1. G. P. Marsh, Man and Nature (Belknap Press of Harvard Univ. Press, Cambridge, MA, 1864).

2. P. M. Vitousek, H. A. Mooney, ]. Lubchenco, J. M. Melillo, Science 277, 494 (1997).

3. National Research Council, Our Common Journey (National Academy Press, Washington, DC, 1999).

4. W. L. Thomas Jr., Man's Role in Changing the Face of the Earth (Univ. of Chicago Press, Chicago, IL, 1956).

5. B. L. Turner II et al., The Earth as Transformed by Human Action: Global and Regional Changes in the Biosphere over the Past 300 Years (Cambridge Univ. Press, Cambridge, UK, 1990).

6. S. H. Schneider, R. Londer, The Coevolution of Climate and Life (Sierra Club Books, San Francisco, CA, 1984).

7. F. Berkes, ]. Colding, C. Folke, Eds., Navigating Social-Ecological Systems: Building Resilience for Complexity and Change (Cambridge Univ. Press, Cambridge, UK, 2003).

8. E. A. Rosa, T. Dietz, Int. Soc. 13, 421 (1998).

9. S. A. Levin, Fragile Dominion: Complexity and the Commons (Perseus Publishing, Cambridge, MA, 1999).
10. L. H. Gunderson, C. S. Holling, Eds., Panarchy: Understanding Transformations in Human and Natural Systems (Island Press, Washington, DC, 2002).

11. L. Schultz, C. Folke, P. Olsson, Environ. Conserv. 34, 140 (2007).

12. S. R. Carpenter et al., Bioscience 57, 323 (2007).

13. ]. Liu et al., in People and the Environment: Approaches for Linking Household and Community Surveys to Remote Sensing and GIS, ]. Fox, V. Mishra, R. Rindfuss, S. Walsh, Eds. (Kluwer Academic Publishers, Boston, MA, 2003), pp. 241-263.

14. E. F. Moran, E. Ostrom, Seeing the Forest and the Trees: Human Environment Interactions in Forest Ecosystems (MIT Press, Cambridge, MA, 2005).

15. M. Alberti et al., Landsc. Urban Plan. 80, 345 (2007)

16. J. Liu et al., Conserv. Biol. 13, 1360 (1999).

17. L. An, M. Linderman, A. Shortridge, J. Qi, J. Liu, Ann. Assoc. Am. Geogr. 95, 54 (2005).

18. M. A. Alberti, Int. Reg. Sci. Rev. 28, 168 (2005).

19. M. D. Oleyar, A. L. Greve, ]. C. Withey, A. M. Bjorn, (www. urbaneco.washington.edu/publications/oleyar_etal.pdf).

20. F. Berkes et al., Science 311, 1557 (2006)

21. ]. Marzluff, Urban Ecosyst. 8, 157 (2005).

22. W. A. Brock, in Punctuated Equilibrium and the Dynamics of U.S. Environmental Policy, R. Repetto, Ed. (Yale Univ. Press, New Haven, CT, 2006), pp. 47-77.

23. P. Olsson, C. Folke, T. Hahn, Ecol. Soc. 9(4), 2 (2004).

24. J. Liu et al., Science 292, 98 (2001).

25. J. Liu, G. Daily, P. Ehrlich, G. Luck, Nature 421, 530 (2003).

26. M. Alberti et al., 2005 Landscape Benchmarks (Washington State CTED, Olympia, WA, 2005).

27. L. An, G. M. He, Z. Liang, ]. Liu, Biodivers. Conserv. 15, 2343 (2006).

28. B. Walker, A. J. Meyers, Ecol. Soc. 9(2), 3 (2004)

29. C. Folke, Glob. Environ. Change 16, 253 (2006).

30. S. D. McCracken et al., Photogrammetric Eng. Remote Sens. 65, 1311 (1999)

31. J. J. Magnuson, T. K. Kratz, B. J. Benson, Eds., Long-Term Dynamics of Lakes in the Landscape (Oxford Univ. Press, Oxford, UK, 2006).

32. The Lake Futures Project (http://lakefutures.wisc.edu).

33. Millennium Ecosystem Assessment (www.MAweb.org).

34. P. Olsson et al., Ecol. Soc. 11(1), 18 (2006).

35. S. R. Carpenter, C. Folke, Trends Ecol. Evol. 21, 309 (2006)

36. ]. Liu, ]. Diamond, Nature 435, 1179 (2005).

37. O. Young et al., Glob. Environ. Change 16, 304 (2006).

38. G. G. Sass et al., Fisheries 31, 321 (2006).

39. We thank T. Baerwald for his support and inspiration for this paper. We also thank R. May and three anonymous reviewers for constructive comments and suggestions; E. Brondizio, N. Reo, and L. VanWey for their helpful input; and S. Li for her able editorial assistance. We acknowledge ]. Marzluff for providing data for Fig. 3 as well as numerous collaborators and students for their contributions to data collection and analysis in the projects described here. Financial support was provided by NSF (Dynamics of Coupled Natural and Human Systems, and North Temperate Lakes Long-Term Ecological Research site), NIH, National Aeronautics and Space Administration, National Natural Science Foundation of China, Michigan State University (Michigan Agricultural Experimental Station, Rachel Carson Chair in Sustainability, University Distinguished Professorship, and Environmental Research Initiative), Swedish Research Council for the Environment, Agricultural Sciences and Spatial Planning, and Swedish Foundation for Strategic Environmental Research.

\section{Supporting Online Material}

www.sciencemag.org/cgi/content/full/317/5844/1513/DC1 Table S1

10.1126/science. 1144004 
If you wish to distribute this article to others, you can order high-quality copies for your colleagues, clients, or customers by clicking here.

Permission to republish or repurpose articles or portions of articles can be obtained by following the guidelines here.

The following resources related to this article are available online at www.sciencemag.org (this information is current as of September 1, 2015 ):

Updated information and services, including high-resolution figures, can be found in the online version of this article at:

http://www.sciencemag.org/content/317/5844/1513.full.html

Supporting Online Material can be found at:

http://www.sciencemag.org/content/suppl/2007/09/11/317.5844.1513.DC1.html

This article cites 22 articles, 3 of which can be accessed free:

http://www.sciencemag.org/content/317/5844/1513.full.html\#ref-list-1

This article has been cited by 59 articles hosted by HighWire Press; see:

http://www.sciencemag.org/content/317/5844/1513.full.html\#related-urls

This article appears in the following subject collections:

Ecology

http://www.sciencemag.org/cgi/collection/ecology 